\title{
The burden of disease associated with being African-American in the United States and the contribution of socio-economic status
}

\author{
Peter Franks ${ }^{\mathrm{a}, *}$, Peter Muennig ${ }^{\mathrm{b}}$, Erica Lubetkin ${ }^{\mathrm{c}}$, Haomiao Jia ${ }^{\mathrm{d}}$ \\ ${ }^{\mathrm{a}}$ Family \& Community Medicine, Center for Health Services Research in Primary Care Department, University of California, \\ 4860 Y Street, Suite 2300, Davis Sacramento, CA 95817, USA \\ ${ }^{\mathrm{b}}$ Columbia University, USA \\ ${ }^{\mathrm{c} C i t y}$ University of New York Medical School, USA \\ ${ }^{\mathrm{d}}$ Mercer University School of Medicine, USA
}

Available online 21 November 2005

\begin{abstract}
The burden of disease associated with being African-American in the US, and the contribution of socio-economic status (SES) to that burden have not been quantified. We derived burden of disease estimates for African-Americans and whites by age group, with and without adjustment for SES (income and education). We used (1) EQ-5D Index scores from the 2000 US Medical Expenditure Panel Survey to derive quality-adjusted life year (QALY) compatible estimates of health-related quality of life (HRQL); (2) 1990-1992 US National Health Interview Survey data linked to National Death Index data through 1995 to derive mortality risks; and (3) 2000 US mortality data from the National Center for Health Statistics to derive current mortality estimates for the US population. We found that relative to whites, African-Americans suffer 67,000 more deaths annually, resulting in 2.2 million years of life lost, and 1.1 million years after SES adjustment. Total QALYs lost (HRQL and mortality) dropped from 2.3 million to 902,000 after SES adjustment. SES differences between African-Americans and whites appear to explain all the HRQL disparity but only half the mortality disparity. Better understanding of the disparate effects of SES may inform interventions to address health disparities adversely affecting African-Americans.
\end{abstract}

(C) 2005 Elsevier Ltd. All rights reserved.

Keywords: USA; African-American; Burden of disease; Mortality; Health-related quality of life

\section{Introduction}

African-Americans are at significantly greater risk of morbidity and premature mortality than

\footnotetext{
*Corresponding author. Tel.: + 19167345494 ; fax: +19167345641 .

E-mail addresses: pfranks@ucdavis.edu (P. Franks), pm124@columbia.edu (P. Muennig), Lubetkin@med.cuny.edu (E. Lubetkin), haomia@yahoo.com (H. Jia).
}

whites, with most studies showing a $30 \%$ higher age-adjusted risk of mortality (Arias, Anderson, Kung, Murphy, \& Kochanek, 2003). Socio-economic status (SES) accounts for much of this difference, but differences in mortality persist after adjustment (Kawachi, Daniels, \& Robinson, 2005; Williams, 1999). A higher prevalence of hypertension, HIV, ischemic heart disease, stroke, and cancer appears to be driving higher rates of mortality in this group 
(Sorlie, Rogot, Anderson, Johnson, \& Backlund, 1992; Wong, Shapiro, Boscardin, \& Ettner, 2002).

To our knowledge, the burden of disease among African-Americans in the US has not been reported. Burden of disease analyses provide useful information on overall societal impact of illness, ideally combining information on both morbidity and mortality (Field \& Gold, 1998; Michaud, Murray, \& Bloom, 2001). Recently, it has become possible to quantify the overall annual and lifetime morbidity and mortality in a single measure, the qualityadjusted life year (QALY).

The QALY is based on a subjective quantification of illness called health-related quality of life (HRQL). The advantages of using HRQL scores are that: (1) they can be used to adjust years of life lived and lost, thereby producing a summary measure that captures both morbidity and mortality in a single number; (2) they capture the cumulative effects of multiple conditions; and (3) they capture both psychological and physiological dimensions of illness. Because they are based on perceptions and include psychological dimensions of illness, however, two individuals with the same biomedical disease of the same severity can report different scores. Further, HRQL scores cannot capture morbidity not affecting health perceptions.

Quantification of the burden of disease due to race and the influence of SES on this burden may assist policymakers in prioritizing social interventions (Field \& Gold, 1998). In this study, we examine the burden of disease borne by AfricanAmericans relative to whites before and after adjusting for income and education. We use comprehensive outcome measures, including annual years of life lost (YLL) and years lost to HRQL impairments. We also examine the losses among individuals over a lifetime. Finally, we examine racial differences in mortality and HRQL by gender and SES.

\section{Methods}

\section{Overview and definitions}

In this study, we examine life expectancy and quality-adjusted life expectancy (QALE) among adult African-Americans relative to whites, excluding Hispanics, before and after adjusting for SES. We also examine annual losses, including the number of deaths, the YLL, and QALYs lost to HRQL impairments alone.
A QALY is a summary measure of population health that includes both morbidity and mortality. One QALY is equal to 1 year of life lived in perfect health, and QALE is the life expectancy in perfect health. The calculation of QALE is achieved using HRQL scores, which provide an assessment of the perceived importance people place on the morbidity associated with illness. These scores assume a value anchored at 1 (perfect health) and 0 (death). A simplified estimation of QALE is the product of life expectancy and the average HRQL score.

\section{Datasets}

We obtained HRQL values from the 2000 Medical Expenditure Panel Survey (MEPS, accessed 03/14/2005, http://www.meps.ahrq.gov/), and mortality ratios from the 1990-1992 National Health Interview Surveys (NHIS, accessed 03/14/2005, http://www.cdc.gov/nchs/nhis.htm) linked to the National Death Index through the end of 1995 (NDI, accessed 03/14/2005, http://www.cdc.gov/ nchs/r\&d/nchs_datalinkage/nhis_data_linkage_activities.htm). The MEPS sample is a subset of the NHIS survey, so these surveys provide comparable nationally representative data of the non-institutionalized civilian population of the United States. Respondents in the surveys self-define their race.

The MEPS, conducted by the Agency for Health Research and Quality, includes detailed sociodemographic, health care utilization, and health status information. The household income data were recoded into discrete categories relating household income to the federal poverty level $(<100 \%$, $100-124 \%, 125-199 \%, 200-399 \%$, and $\geqslant 400 \%$ ). Individual educational attainment data were recoded into four discrete categories $(<12$ years, 12 years, $13-15$ years, and $\geqslant 16$ years).

In 2000, the MEPS included, for persons over age 18 , five questions that can be used to generate the EuroQol EQ-5D Index (Cohen, 2003), a QALY compatible and preference-based instrument (Rabin $\&$ de Charro, 2001). The EQ-5D Index assesses: (1) mobility, (2) self-care, (3) ability to perform usual activities, (4) pain or discomfort, and (5) anxiety or depression. Each dimension is scaled as "no problem," "some problem," or "extreme problem." EQ-5D Index scores were obtained from a representative sub-sample of 14,382 African-American and white adults. Responses to the five EQ-5D questions were transformed into preference weighted HRQL scores, using recently published 
US preference weights (Shaw, Johnson, \& Coons, 2005).

The NHIS contains similar socio-demographic variables to those in the MEPS and can be linked to NDI data, allowing for mortality analyses of subjects in the original sample. The 1990-1992 NHIS linked data sampled 256,900 adults, 11,214 of whom died by the end of 1995 .

\section{Calculations}

Analyses were conducted using STATA (version 8.2, StataCorp, College Station, TX) and SUDAAN (version 8.0.1, Research Triangle Institute, Research Triangle Park, NC) statistical packages that allow adjustment for the complex sampling design used in the MEPS and NHIS.

Linear regressions were used to derive age-group specific EQ-5D Index scores for persons 18 and older. Cox proportional hazard survival models were used to generate the hazard ratios (HRs). Analyses compared African-Americans relative to white subjects with and without adjusting for SES (income and education categories). Age groups used the following age intervals: $<25,25-44,45-64$, $65-74$, and $75+$. Each analysis also adjusted for age and age squared.

Abridged life tables were generated for AfricanAmericans and whites for the year 2000 using age intervals of 5 years (or less) to age 90 and over. These tables were populated using mortality data obtained from the National Center for Health Statistics (Anderson, 2000; Minino, Arias, Kochanek, Murphy, \& Smith, 2002). Life tables are constructed using a hypothetical cohort of 100,000 individuals exposed to a risk of death over each age interval. For instance, if the risk of death between age 0 and 1 is 0.00693 , then $0.00693 \times 100,000=$ 693 persons will die over this interval, leaving $100,000-693=99,307$ persons to be exposed to the risk of death for persons aged 1-4. To calculate life expectancy at birth, the number of person years in each age interval are summed and divided by the number of persons at the start of the first interval $(100,000)$.

These tables used 2000 mortality data and calculated life expectancy for that year. The age group HRs generated from NHIS data were then multiplied by the mortality rates in the life tables to obtain rates adjusted for SES. This was done to estimate life expectancy for persons in each selfidentified race group.
This technique assumes that HRs of mortality between the race groups under study, and the relative effects of education and income, have not changed between the 1990-1995 NHIS sample follow-up and the year 2000. To calculate QALE, the number of person years in each interval is multiplied by the mean HRQL score for that interval. These health-adjusted person years are again summed over all age intervals and divided by the persons at the start of the first interval. Further details pertaining to the general construction of our life tables have been published elsewhere (Anderson, 2000; Muennig, 2002).

Race-related deaths were calculated as follows:

$\sum_{x=1}^{5} M_{x} e_{x} /\left(1-p_{x}\right)$,

where $M$ is the total number of deaths in age interval $x, e$ the proportion of $M$ excess deaths in age interval $x$, and $p$ the proportion of AfricanAmericans in age interval $x$. Total deaths were obtained from death certificate data (Minino et al., 2002). In 2000, there were 1,301,202 deaths among African-American and white adults.

Total YLL were calculated as

$\sum_{x=1}^{5} D_{x} L_{x}$

where $x$ is the age interval $(<25,25-44,45-64$, $65-74$, and $75+), D_{x}$ is the number of race-related deaths within age interval $x$ and $L_{x}$ is the life expectancy for white persons at the mid-point of age interval $x . L_{x}$ was obtained from life table values for the reference group (whites) to reflect the full potential life lost.

Total QALYs lost to morbidity were calculated as

$\sum_{x=1}^{5}\left(H_{A x}-H_{B x}\right) P_{x}$,

where $H_{A x}$ is the HRQL score for whites in age interval $x, H_{B x}$ is the HRQL score for AfricanAmericans, and $P_{x}$ is the African-American population in age interval $x$. Differences were also calculated for the African-American population and white population adjusted for SES.

Total QALYs (due to both morbidity and mortality) were calculated as

$\sum_{x=1}^{5} Q_{M x}+H_{x} Y_{x}$, 
where $Q_{M x}$ is the total number of QALYs due to morbidity in age interval $x, H_{x}$ is the HRQL score for persons in the BMI category of interest in age interval $x$, and $Y_{x}$ is the number of YLL in age interval $x$.

\section{Gender differences}

Limited sample size precluded producing burden of disease estimates by age and gender. However, it was possible to age-adjust HRs and then apply the formula for race-related deaths for all age groups together in a secondary analysis. While this method is known to overestimate total deaths when hazards decline with age, it will produce proportionate breakdown in deaths by gender as long as hazards decline similarly for males and females (Flegal, Graubard, \& Williamson, 2004). Likewise, we estimated total QALYs lost to morbidity by gender using an age-adjusted analysis.

\section{Results}

Table 1 shows the demographic profile of the MEPS sample for the US overall, for AfricanAmericans, and whites. African-Americans were more likely to be younger, female, unmarried, live in a metropolitan statistical area, be uninsured, have worse self-rated health, and have two or more conditions than whites. While African-Americans are about $40 \%$ less likely to be married than whites, the likelihood of being a widow is roughly the same for both groups. In this sample, the AfricanAmerican group was also more likely to report having diabetes and hypertension, but not asthma or heart disease.

Table 2 shows HRQL scores and HRs for all groups under study. The gap in HRQL due to morbidity between African-Americans and whites is small with or without SES adjustment. Conversely, the HRs show a marked racial disparity, particularly for younger persons, an effect that is noticeably attenuated by SES adjustment.

Table 3 shows the annual burden of disease among African-Americans relative to whites before and after adjusting for SES. African-Americans experience about 67,000 more deaths than they would have had their mortality rates been similar to whites. This translates into 2.2 million more YLL. After adjusting for SES, these numbers drop to about 38,000 lives and 1.1 million YLL. Thus, roughly 29,000 of the lives lost and 1.1 million years
Table 1

Basic demographic characteristics of the African-American (AA) and white populations (White) relative to the average person (Total) in the 2000 Medical Expenditure Panel Survey

\begin{tabular}{|c|c|c|c|}
\hline & Total & AA & White \\
\hline \multicolumn{4}{|l|}{ Age } \\
\hline $18-44$ & 51.7 & 58.4 & 48.2 \\
\hline $45-64$ & 31.4 & 29.4 & 32.8 \\
\hline $65+$ & 16.9 & 12.2 & 19.0 \\
\hline \multicolumn{4}{|l|}{ Sex } \\
\hline Male & 47.7 & 43.5 & 47.9 \\
\hline Female & 52.2 & 56.4 & 52.1 \\
\hline \multicolumn{4}{|l|}{ Marital status } \\
\hline Married & 57.4 & 37.3 & 60.4 \\
\hline Widowed & 7.2 & 7.2 & 7.7 \\
\hline Divorced & 11.7 & 13.6 & 11.9 \\
\hline Separated & 1.7 & 3.8 & 1.2 \\
\hline Never married & 22.0 & 38.1 & 18.8 \\
\hline \multicolumn{4}{|c|}{ Metropolitan statistical area (MSA) } \\
\hline Non-MSA & 19.7 & 13.2 & 22.8 \\
\hline MSA & 80.5 & 86.8 & 77.2 \\
\hline \multicolumn{4}{|l|}{ Insurance } \\
\hline Any private & 74.9 & 64.6 & 79.7 \\
\hline Public only & 13.3 & 19.1 & 12.1 \\
\hline Uninsured & 11.8 & 16.2 & 8.2 \\
\hline \multicolumn{4}{|c|}{ Self-reported health } \\
\hline Fair or poor & 14.7 & 15.9 & 13.8 \\
\hline \multicolumn{4}{|c|}{ Self-reported conditions } \\
\hline Diabetes & 6.5 & 9.2 & 5.9 \\
\hline Asthma & 9.2 & 9.9 & 9.5 \\
\hline Hypertension & 20.4 & 24.6 & 21.2 \\
\hline Heart disease & 10.3 & 8.6 & 11.4 \\
\hline \multicolumn{4}{|c|}{ Number of conditions } \\
\hline 0 & 66.7 & 64.0 & 65.4 \\
\hline 1 & 22.9 & 23.5 & 23.9 \\
\hline $2+$ & 10.5 & 12.5 & 10.7 \\
\hline
\end{tabular}

lost annually may be attributable to differences in income and education between the groups.

Racial differences between adjusted and unadjusted values in the QALY analysis produced paradoxical results. African-Americans lost about 435,000 QALYs to HRQL impairments in 2000 relative to whites. However, after adjusting for SES, African-Americans experience a gain of 45,000 QALYs relative to whites. Total QALYs lost (HRQL impairments and mortality combined) drop from 2.3 million to 902,000 .

Table 4 shows life expectancy and QALE before and after SES adjustment for African-Americans and whites. (Note that these represent changes in 
Table 2

Health-related quality of life (HRQL) and mortality hazard ratios by age-group and race, with and without SES adjustment

\begin{tabular}{|c|c|c|c|}
\hline & \multicolumn{2}{|c|}{ African-Americans } & \multirow{2}{*}{$\begin{array}{l}\text { Whites } \\
\text { Reference }\end{array}$} \\
\hline & Unadjusted & SES-adjusted & \\
\hline \multicolumn{4}{|l|}{ HRQL } \\
\hline $18-25$ & 0.93 & 0.93 & 0.92 \\
\hline $25-44$ & 0.88 & 0.89 & 0.89 \\
\hline $45-64$ & 0.81 & 0.85 & 0.85 \\
\hline $65-74$ & 0.79 & 0.82 & 0.81 \\
\hline$>75$ & 0.71 & 0.74 & 0.75 \\
\hline \multicolumn{4}{|c|}{ Hazard ratio (African-American vs. white) } \\
\hline $18-25$ & 2.69 & 2.07 & \\
\hline $25-44$ & 2.15 & 1.57 & \\
\hline $45-64$ & 1.68 & 1.28 & \\
\hline $65-74$ & 1.35 & 1.17 & \\
\hline$>75$ & 1.16 & 1.13 & \\
\hline
\end{tabular}

QALYs over an individual's lifetime rather than total annual changes.) Life expectancy at birth for African-Americans was 71.4 years in 2000 and 77.2 years for their white counterparts. After adjusting for SES, the difference in life expectancy at birth drops from approximately 6 years to about 3 years. QALE differences at age 18 drop from approximately 3 years to about 1 year.

\section{Gender differences}

Using age-adjusted analyses by gender we observed similar risks for African-Americans of both genders (relative to whites of both genders); for men the adjusted $\mathrm{HR}=1.48(95 \%$ confidence interval $[\mathrm{CI}]=1.36,1.61)$ and for women the adjusted $\mathrm{HR}=1.46(95 \% \mathrm{CI}=1.35,1.59)$. After adjusting for SES, the male $\mathrm{HR}=1.23(95 \% \mathrm{CI}=1.12,1.39)$ and the female $\mathrm{HR}=1.32(95 \% \mathrm{CI}=1.22,1.44)$. Although these figures suggest a more profound effect of SES on African-American men, the wide overlap of the confidence intervals suggests these differences are not statistically significant. Further, analyses including an interaction term between gender and race revealed that the interaction was not statistically significant without $(p>0.8)$ or with $(p>0.7)$ SES adjustment.

An analysis of the age-adjusted relationship between race and EQ-5D scores using ordinary least-squares regression revealed that AfricanAmericans had lower HRQL scores than whites $(-0.015,95 \% \mathrm{CI}=-0.027,-0.004)$, an effect that
Table 3

Race-associated burden of disease before and after controlling for socio-economic status (SES) for the year 2000

\begin{tabular}{|c|c|c|}
\hline & \multicolumn{2}{|c|}{ SES adjustment } \\
\hline & Unadjusted & Adjusted \\
\hline \multicolumn{3}{|c|}{ Lives lost } \\
\hline$<25$ & 3000 & 2000 \\
\hline $25-44$ & 14,000 & 7000 \\
\hline $45-64$ & 29,000 & 10,000 \\
\hline $65-74$ & 10,000 & 6000 \\
\hline$>75$ & 11,000 & 12,000 \\
\hline Total & 67,000 & 38,000 \\
\hline \multicolumn{3}{|c|}{ Years of life lost } \\
\hline$<25$ & 189,000 & 145,000 \\
\hline $25-44$ & 646,000 & 335,000 \\
\hline $45-64$ & $1,053,000$ & 382,000 \\
\hline $65-74$ & 203,000 & 114,000 \\
\hline$>75$ & 120,000 & 130,000 \\
\hline Total & $2,210,000$ & $1,106,000$ \\
\hline \multicolumn{3}{|c|}{ QALYs (morbidity) } \\
\hline$<25$ & $-35,000$ & $-41,000$ \\
\hline $25-44$ & 104,000 & 0 \\
\hline $45-64$ & 302,000 & 0 \\
\hline $65-74$ & 29,000 & $-16,000$ \\
\hline$>75$ & 35,000 & 12,000 \\
\hline Total & 435,000 & $-45,000$ \\
\hline \multicolumn{3}{|c|}{ QALYs (total) } \\
\hline$<25$ & 140,000 & 94,000 \\
\hline $25-44$ & 672,000 & 299,000 \\
\hline $45-64$ & $1,155,000$ & 325,000 \\
\hline $65-74$ & 189,000 & 77,000 \\
\hline$>75$ & 120,000 & 108,000 \\
\hline Total & $2,277,000$ & 902,000 \\
\hline
\end{tabular}

Notes: QALYs are quality-adjusted health years. HRQL is health-related quality of life. Total is combined HRQL impairments and mortality effects. Numbers rounded to nearest thousand.

Table 4

Life expectancy and health-adjusted life expectancy by race and socio-economic status (SES), 2000

\begin{tabular}{llll}
\hline & \multicolumn{2}{c}{ African-Americans } & \multirow{2}{*}{ Whites } \\
\cline { 2 - 3 } & \multicolumn{2}{c}{ Unadjusted } & SES adjusted Reference \\
& & & \\
\hline Life expectancy, birth & 71.4 & 74.1 & 77.2 \\
Life expectancy, at age 18 & 55.2 & 57.5 & 59.9 \\
QALE $^{\mathrm{a}}$, at age 18 & 46.0 & 48.0 & 49.2 \\
\hline
\end{tabular}

${ }^{\text {a }}$ Quality-adjusted life expectancy.

was statistically significant in women $(-0.019,95 \%$ $\mathrm{CI}=-0.034,-0.005)$, but not men $(-0.009,95 \%$ $\mathrm{CI}=-0.026,0.008)$. However, the interaction 
between race and gender was not significant. After SES adjustment the racial disparity became nonsignificant overall $(0.005,95 \% \mathrm{CI}=-0.007,0.017)$ and by gender.

\section{Discussion}

Relative to whites, African-Americans suffer 67,000 more deaths annually, resulting in 2.2 million YLL. YLL drop to 1.1 million after adjustment for SES. Total QALYs fall more dramatically with SES adjustment, dropping from 2.3 million to 902,000 . This larger drop is attributable to the apparent obliteration of race disparities in HRQL after SES adjustment. The disparate effects of SES on mortality and morbidity differences in AfricanAmericans and whites have also been noted previously. Analyzing the 1987 National Medical Expenditure Survey together with 5-year mortality follow-up data, Franks et al. found that SES explained the racial disparity in morbidity (using a non-QALY compatible measure similar to the SF20) but less of the disparity in mortality (Franks, Gold, \& Fiscella, 2003).

In contrast to the profound racial differences in mortality, the racial differences in HRQL are quite small, with or without adjustment for SES. We observed an age-adjusted difference in EQ-5D scores of 0.015 , which became non-significant after SES adjustment. What constitutes a minimally clinically significant difference in preference scores is debatable (Kathleen et al., 2005; Walters \& Brazier, 2005); however, this difference is well below the threshold of 0.03 suggested for several preference-based HRQL measures (Dolan, 1997; Grootendorst, Feeny, \& Furlong, 2000; Walters \& Brazier, 2003).

There are several possible explanations for the apparently different contributions SES makes to HRQL and mortality disparities. As noted in the introduction, HRQL measures, while having the advantage of summarizing the effects of disparate morbidities, can capture only those morbidities affecting perceptions of health. For example, persons with hypercholesterolemia or hypertension may perceive little or no problems with their health.

It is thus possible that the relatively small racial differences in the EQ-5D scores we observed are attributable to differences in the causes of disease by race. Hypertension, stroke, ischemic heart disease, and trauma are major causes of morbidity and mortality that are far more common in African-
Americans than whites (Wong et al., 2002); however, until these conditions cause a major morbid or mortal event they may have little impact on HRQL. These conditions also tend to kill subjects faster than others, sometimes via sudden death. Further, the adverse consequences of hypertension may be accelerated by the increased risk of undertreated and undiagnosed disease suffered by AfricanAmericans compared with whites (Lopes et al., 2003). Thus, adjusting for SES, African-Americans may perceive less dysfunction than whites (as captured by the EQ-5D) but be at increased risk for premature, sudden mortality.

While the EQ-5D provides relatively clear categories for self-reported dysfunction (e.g., no problems in mobility, some problems, or severe problems/unable to), differences in reporting can nonetheless occur. For instance, one person with a slight limp might report no problems while another might report some problems. It is therefore possible that African-Americans respond to EQ-5D questions differently than do whites, in a way that underestimates their true disease burden. The evidence for such differential item responding or functioning (DIF) between African-Americans and whites is mixed. DIF has been reported for the SF12 questionnaire in the same MEPS data we used to estimate EQ-5D scores (Fleishman \& Lawrence, 2003). The authors found evidence of DIF for mental health functioning, with African-Americans reporting apparently better mental health than whites, but not for physical health functioning. However, the size of the DIF effect in that study was small and would not fully explain our findings. We are not aware of any published evidence indicating DIF by racial groups for the EQ-5D. Our unpublished analyses of MEPS did not suggest any substantive evidence of DIF with regard to the EQ-5D (details available from the authors). Conversely, Bonham et al. reported an association between John Henryism (the predisposition to directly confront racism) and better self-reported physical health in African-American men (Bonham, Sellers, \& Neighbors, 2004). While the role of John Henryism in health is controversial, it is possible that the average HRQL reported by AfricanAmericans is higher than might be reported in the absence of racism. In turn, this would spuriously diminish the apparent effects of morbidity on African-Americans. Given the important role of HRQL measures in policy analyses, and potential implications for resource allocation of differential 
responding by African-Americans and whites, clarification of this issue is critical.

Given that HRQL has been found to be a strong predictor of mortality (Idler \& Benyamini, 1997), it may seem counterintuitive that African-Americans suffer greater mortality than whites but have a similar HRQL. However, this disjunction parallels the relationships observed for men and women. Thus, men report better HRQL than women, but have a shorter average life expectancy (Franks et al., 2003). The gender disjunction between HRQL and mortality may reflect differences in culturally defined gender roles that make acknowledging dysfunction more difficult for men. It also reflects the greater prevalence of non-fatal diseases in women. These gender effects suggest a possible mechanism for the disjunction between HRQL and mortality effects for African-Americans compared with whites. However, our age-adjusted analyses revealed no interaction between race and gender effects, suggesting that gender does not mediate the race disjunction between the HRQL and mortality.

While there was no significant difference in HRQL after adjusting for SES, we did find significant differences in mortality by race, differences that persisted after controlling for SES. Differences in the burden of disease between African-Americans and whites presumably reflect socio-economic effects, the effects of racism on health, and/or genetic differences. There has been recent renewed interest in exploring the role of genetic factors in understanding differences between African-Americans and whites (Bamshad, 2005). This is an area of great controversy partly because racists have historically used false genetic arguments to justify discriminatory policies, such as forced sterilization, housing discrimination, and other forms of mistreatment. There is also concern that attributing disparities between African-Americans and whites to genetic differences may undermine efforts to reduce disparities (Pearce, Foliaki, Sporle, \& Cunningham, 2004; Sankar et al., 2004).

The recent release of a drug combination (nitrate/ hydralazine) to treat heart failure in AfricanAmericans has fueled this controversy (Taylor et al., 2004). However, the finding that this drug combination is more effective in African-Americans than whites may point more to the spectrum of the causes of heart failure than to genetic factors. Thus, environmental factors (like racism, and increased SES stress) may contribute to differences between African-Americans and whites in the biological pathways causing heart failure (for example, small vs. large vessel involvement), and thus differences in the responses to drugs. Currently, there is little evidence that genetic factors play a role in the burden of disease of African-Americans. However, research on these issues may yield a more complete understanding about the causes and possible remedies for the health disparities.

In contrast, there is much more evidence that racism and socio-economic factors account for the health disparities (Williams, 1999). These factors also interact with each other, compounding their adverse effects on the health of African-Americans. Kunitz and Pesis-Katz (2005) have shown how slavery, residential segregation and persisting racism contribute to the adverse health effects besetting African-Americans. Perceived racism has also been shown to have adverse health effects, with AfricanAmericans reporting racism exhibiting higher blood pressure than those who do not (Krieger \& Sidney, 1996). Also, perceived inequality may increase stress hormone levels or stress reactivity, providing a biological pathway for disease (Markowe et al., 1985; McEwen, 1998; Williams, 1999). Skepticism, anger, weaker social networks, less civic participation, and lower perceived social status are all associated with a higher risk of morbidity and premature mortality (Fiscella, Franks, Clancy, Doescher, \& Banthin, 1999; Kawachi \& Berkman, 2001).

African-Americans have been found to have lower levels of trust in their physicians and to be more passive in encounters (Bird \& Bogart, 2001; Collins, Clark, Petersen, \& Kressin, 2002; Doescher, Saver, Franks, \& Fiscella, 2000). Likewise, physicians perceive and treat African-American patients differently than their white counterparts (Bogart, Catz, Kelly, \& Benotsch, 2001; van Ryn \& Burke, 2000). These impediments to optimal patient care likely contribute to poorer outcomes for AfricanAmerican patients. These impediments are also most likely based on unconscious racism in health care, rather than larger structural problems. As such, they may respond to downstream quality improvement interventions (Fiscella, Franks, Gold, \& Clancy, 2000). Several such interventions show promise of reducing disparities in health care outcomes, including for immunizations (Szilagyi et al., 2002; Zimmerman et al., 2003), and care for renal failure (Sehgal, 2003), breast cancer (Shapiro, Venet, Strax, Venet, \& Roeser, 1982), hypertension (Hypertension Detection and Follow-up Program 
Cooperative Group, 1979), diabetes (Goldman \& Smith, 2002), and depression (Smith, Rost, Nutting, Elliott, \& Dickinson, 2002). Further downstream interventions are needed that directly address disparities.

The $50 \%$ reduction in disease burden observed after SES adjustment is likely an underestimate of the impact of SES on racial disparities. First, income does not capture wealth, and wealth at given income levels is lower in African-Americans than whites (Kunitz \& Pesis-Katz, 2005). Second, our measure of education, years of schooling, incompletely captures differences in school quality. Other proximal and distal environmental effects, also incompletely captured, include poorer and more toxic neighborhoods, fewer job opportunities (Lillie-Blanton, Parsons, Gayle, \& Dievler, 1996; Williams, 1999), and possibly poorer health care (Bach, Pham, Schrag, Tate, \& Hargraves, 2004). Clearly, addressing the health effects of disparities in SES will go a long way toward mitigating health disparities between African-Americans and whites. We have addressed elsewhere the burden of disease associated with low income, which we estimated to be over 17 million QALYs, much larger than the 2 million attributable to race disparities (Muennig, Franks, Jia, Lubetkin, \& Gold, 2005). Thus, while addressing the effects of income disparities will likely have a profound impact on race disparities, the converse is unlikely to be true. Issacs and Schroeder (Isaacs \& Schroeder, 2004) have pointed out how class is a relatively ignored aspect of disparities in the US policy debate. In contrast to the likely beneficial effects of downstream quality improvement interventions on racial disparities related to differences in health care, interventions to address these SES disparities in health will also need to address the upstream structural problems underpinning these disparities. In England, the Acheson report suggested enacting redistributive policy reforms in order to improve health (Acheson, 1998). Some recommended policy changes have been implemented, but outcome data are pending (Marmot, 2004). While existing studies are promising (Katz, Kling, \& Liebman, 2001; Kehrer \& Wolin, 1979; Schweinhart, 2004), further study is needed to examine the effects of upstream policy change on morbidity and mortality (Mechanic, 2005; Williams \& Jackson, 2005).

There are a number of limitations to this analysis. The foremost limitation is related to the use of HRQL to assess total morbidity. While the approach we used has the advantage of summarizing morbidity effects and capturing aggregate effects across disparate diseases, it is susceptible to a number of problems.

First, HRQL scores may be vulnerable to differences in beliefs and perceptions-factors that may be influenced by cultural factors, income, education level, and race/ethnicity (i.e., the DIF noted above). However, some may view perceived morbidity as more relevant than biologically measured morbidity.

Second, because of differences in the methods by which health states are valued, different generic preference-weighted instruments may produce different HRQL scores, and thus different estimates of the burden of disease (Gold \& Muennig, 2002). Even for the same instrument, different weighting systems can produce dramatically different scores. For instance, the use of US weights compared with UK weights produces EQ-5D Index scores that are systematically higher; thus, the effects of any given morbidity on HRQL using US weights is less than that using UK weights (Johnson, Luo, Shaw, Kind, \& Coons, 2005).

Third, while the EQ-5D displays reasonable reliability and validity when compared to other HRQL measures, the measure has known ceiling effects stemming from the limited number of severity levels assessed (Coons, Rao, Keininger, \& Hays, 2000; Gold et al., 1996). In turn, this ceiling effect may result in underestimation of the full effects of morbidity on HRQL relative to other HRQL measures, especially for mildly impaired health states.

Other limitations relate to our mortality analyses. Inconsistencies have been noted in reporting race and ethnicity on death certificates, but these effects are small (Minino et al., 2002). Also, we calculated the effect of mortality on SES using data from 1990 through 1995 because more recent data were not available to us. However, the relative risk among African-Americans relative to whites has changed little since 1960, suggesting that temporal changes by SES might be small if they exist at all (Minino et al., 2002). Our mortality data are also consistent with those of Satcher et al., who used a different methodology and 2002 data (Satcher et al., 2005). When tested against life tables produced by the NCHS, our models showed little evidence of bias in mortality; the product of age-specific HRs for African-Americans (unadjusted for SES) and 2000 white mortality probabilities produced a life 
expectancy just 0.06 years less than life expectancy produced by actual life tables for AfricanAmericans in 2000. This also serves as evidence suggesting that the HRs have not changed much since 1995.

In summary, this study suggests that the burden of disease suffered by African-Americans in the US is largely embedded in the broader problem of the adverse effects of SES disparities. Beyond these SES effects, racial disparities are most likely related to the effects of racism. While downstream quality improvement interventions may have success in reducing disparities in health care, addressing the adverse effects of SES disparities in health will likely involve upstream structural changes. Research geared toward identifying novel upstream and downstream approaches to reducing both SES and racial disparities in health is greatly needed.

\section{References}

Acheson, D. (1998). Independent inquiry into inequalities in health. London: Stationary Office.

Anderson, R. N. (2000). A method for constructing complete annual US life tables. Vital Health Statistics, 2(129), 1-28.

Arias, E., Anderson, R. N., Kung, H. C., Murphy, S. L., \& Kochanek, K. D. (2003). Deaths: Final data for 2001. National Vital Statistics Report, 52(3), 1-115.

Bach, P. B., Pham, H. H., Schrag, D., Tate, R. C., \& Hargraves, J. L. (2004). Primary care physicians who treat blacks and whites. New England Journal of Medicine, 351, 575-584.

Bamshad, M. (2005). Genetic influences on health: Does race matter? Journal of the American Medical Association, 294(8), 937-946.

Bird, S. T., \& Bogart, L. M. (2001). Perceived race-based and socioeconomic status(SES)-based discrimination in interactions with health care providers. Ethnicity and Disease, 11(3), 554-563.

Bogart, L. M., Catz, S. L., Kelly, J. A., \& Benotsch, E. G. (2001). Factors influencing physicians' judgments of adherence and treatment decisions for patients with HIV disease. Medical Decision Making, 21(1), 28-36.

Bonham, V. L., Sellers, S. L., \& Neighbors, H. W. (2004). John Henryism and self-reported physical health among highsocioeconomic status African American men. American Journal of Public Health, 94(5), 737-738.

Cohen, S. B. (2003). Design strategies and innovations in the medical expenditure panel survey. Medical Care, 41(Suppl. 7), III5-III12.

Collins, T. C., Clark, J. A., Petersen, L. A., \& Kressin, N. R. (2002). Racial differences in how patients perceive physician communication regarding cardiac testing. Medical Care, 40(Suppl. 1), I27-I34.

Coons, S. J., Rao, S., Keininger, D. L., \& Hays, R. D. (2000). A comparative review of generic quality-of-life instruments. Pharmacoeconomics, 17(1), 13-35.
Doescher, M. P., Saver, B. G., Franks, P., \& Fiscella, K. (2000). Racial and ethnic disparities in perceptions of physician style and trust. Archives of Family Medicine, 9(10), 1156-1163.

Dolan, P. (1997). Modeling valuations for EuroQol health states. Medical Care, 35(11), 1095-1108.

Field, M. J., \& Gold, M. R. (1998). Summarizing population health: Directions for the development and application of population metrics. Committee on summary measures of population health. Washington, DC: Institute of Medicine, National Academy Press.

Fiscella, K., Franks, P., Clancy, C. M., Doescher, M. P., \& Banthin, J. S. (1999). Does skepticism towards medical care predict mortality? Medical Care, 37(4), 409-414.

Fiscella, K., Franks, P., Gold, M. R., \& Clancy, C. M. (2000). Inequality in quality: Addressing socioeconomic, racial, and ethnic disparities in health care. Journal of the American Medical Association, 283(19), 2579-2584.

Flegal, K. M., Graubard, B. I., \& Williamson, D. F. (2004). Methods of calculating deaths attributable to obesity. American Journal of Epidemiology, 160(4), 331-338.

Fleishman, J. A., \& Lawrence, W. F. (2003). Demographic variation in SF-12 scores: True differences or differential item functioning? Medical Care, 41(Suppl 7), III75-III86.

Franks, P., Gold, M. R., \& Fiscella, K. (2003). Sociodemographics, self-rated health, and mortality in the US. Social Science \& Medicine, 56(12), 2505-2514.

Gold, M. R., \& Muennig, P. (2002). Measure-dependent variation in burden of disease estimates: Implications for policy. Medical Care, 40(3), 260-266.

Gold, M. R., Siegel, J. E., Russell, L. B., \& Weinstein, M. C. (Eds.). (1996). Cost-effectiveness in health and medicine. New York: Oxford University Press.

Goldman, D. P., \& Smith, J. P. (2002). Can patient selfmanagement help explain the SES health gradient? Proceedings of the National Academy of Sciences of the United States of America, 99(16), 10929-10934.

Grootendorst, P., Feeny, D., \& Furlong, W. (2000). Health Utilities Index Mark 3: Evidence of construct validity for stroke and arthritis in a population health survey. Medical Care, 38(3), 290-299.

Hypertension Detection and Follow-up Program Cooperative Group. (1979). Five-year findings of the hypertension detection and follow-up program. II. Mortality by race-sex and age. Journal of the American Medical Association, 242(3), 2572-2577.

Idler, E. L., \& Benyamini, Y. (1997). Self-rated health and mortality: A review of twenty-seven community studies. Journal of the Health and Social Behavior, 38(1), 21-37.

Isaacs, S. L., \& Schroeder, S. A. (2004). Class-The ignored determinant of the nation's health. New England Journal of Medicine, 351(11), 1137-1142.

Johnson, J. A., Luo, N., Shaw, J. W., Kind, P., \& Coons, S. J. (2005). Valuations of EQ-5D health states: Are the United States and United Kingdom different? Medical Care, 43(3), 221-228.

Kathleen, W. W., Monika, B., Neil, A., Ron, D. H., Donald, L. P., \& Tara, S. (2005). Estimating clinically significant differences in quality of life outcomes. Quality of Life Research, 14(2), 285-295.

Katz, L. F., Kling, J., \& Liebman, J. B. (2001). Moving to opportunity in Boston: Early results of a randomized mobility experiment. Quarterly Journal of Economics, 116(2), 607-654. 
Kawachi, I., \& Berkman, L. F. (2001). Social ties and mental health. Journal of Urban Health, 78(3), 458-467.

Kawachi, I., Daniels, N., \& Robinson, D. E. (2005). Health disparities by race and class: Why both matter. Health Affairs (Millwood), 24(2), 343-352.

Kehrer, B. H., \& Wolin, C. M. (1979). Impact of income maintenance on low birth weight: Evidence from the Gary Experiment. Journal of Human Resources, 14(4), 434-462.

Krieger, N., \& Sidney, S. (1996). Racial discrimination and blood pressure: The CARDIA Study of young black and white adults. American Journal of Public Health, 86, 1370-1378.

Kunitz, S. J., \& Pesis-Katz, I. (2005). Mortality of white Americans, African Americans, and Canadians: The causes and consequences for health of welfare state institutions and policies. Milbank Quarterly, 83(1), 5-39.

Lillie-Blanton, M., Parsons, P. E., Gayle, H., \& Dievler, A. (1996). Racial differences in health: Not just black and white, but shades of gray. Annual Review of Public Health, 17, 411-448.

Lopes, A. A., James, S. A., Port, F. K., Ojo, A. O., Agodoa, L. Y., \& Jamerson, K. A. (2003). Meeting the challenge to improve the treatment of hypertension in blacks. Journal of Clinical Hypertension (Greenwich), 5(6), 393-401.

Markowe, H. L., Marmot, M. G., Shipley, M. J., Bulpitt, C. J., Meade, T. W., Stirling, Y., et al. (1985). Fibrinogen: A possible link between social class and coronary heart disease. British Medical Journal (Clinical Research Edition), 291(6505), 1312-1314.

Marmot, M. G. (2004). Tackling health inequalities since the Acheson inquiry. Journal of Epidemiology and Community Health, 58(4), 262-263.

McEwen, B. S. (1998). Protective and damaging effects of stress mediators. New England Journal of Medicine, 338(3), 171-179.

Mechanic, D. (2005). Policy challenges in addressing racial disparities and improving population health. Health Affairs (Millwood), 24(2), 335-338.

Michaud, C. M., Murray, C. J., \& Bloom, B. R. (2001). Burden of disease-Implications for future research. Journal of the American Medical Association, 285(5), 535-539.

Minino, A. M., Arias, E., Kochanek, K. D., Murphy, S. L., \& Smith, B. L. (2002). Deaths: Final data for 2000. National Vital Statistics Report, 50(15), 1-119.

Muennig, P. (2002). Designing and conducting cost-effectiveness analyses in medicine and health care. San Francisco: JosseyBass.

Muennig, P., Franks, P., Jia, H., Lubetkin, E., \& Gold, M. R. (2005). The income-associated burden of disease in the United States. Social Science \& Medicine, 61(9), 2018-2026.

Pearce, N., Foliaki, S., Sporle, A., \& Cunningham, C. (2004). Genetics, race, ethnicity, and health. British Medical Journal, 328(7447), 1070-1072.

Rabin, R., \& de Charro, F. (2001). EQ-5D: A measure of health status from the EuroQol Group. Annals of Medicine, 33(5), 337-343.

Sankar, P., Cho, M. K., Condit, C. M., Hunt, L. M., Koenig, B., Marshall, P., et al. (2004). Genetic research and health disparities. Journal of the American Medical Association, 291(24), 2985-2989.
Satcher, D., Fryer, G. E., Jr., McCann, J., Troutman, A., Woolf, S. H., \& Rust, G. (2005). What if we were equal? A comparison of the black-white mortality gap in 1960 and 2000. Health Affairs (Millwood), 24(2), 459-464.

Schweinhart, L. (2004). The high/scope perry preschool study through age 40. Ypsilanti: High/Scope.

Sehgal, A. R. (2003). Impact of quality improvement efforts on race and sex disparities in hemodialysis. Journal of the American Medical Association, 289(8), 996-1000.

Shapiro, S., Venet, W., Strax, P., Venet, L., \& Roeser, R. (1982). Prospects for eliminating racial differences in breast cancer survival rates. American Journal of Public Health, 72, 1142-1145.

Shaw, J. W., Johnson, J. A., \& Coons, S. J. (2005). US valuation of the EQ-5D health states: Development and testing of the D1 valuation model. Medical Care, 43(3), 203-220.

Smith, J. L., Rost, K. M., Nutting, P. A., Elliott, C. E., \& Dickinson, L. M. (2002). Impact of ongoing primary care intervention on long term outcomes in uninsured and insured patients with depression. Medical Care, 40(12), 1210-1222.

Sorlie, P., Rogot, E., Anderson, R., Johnson, N. J., \& Backlund, E. (1992). Black-white mortality differences by family income. The Lancet, 340(8815), 346-350.

Szilagyi, P. G., Schaffer, S., Shone, L., Barth, R., Humiston, S. G., Sandler, M., et al. (2002). Reducing geographic, racial, and ethnic disparities in childhood immunization rates by using reminder/recall interventions in urban primary care practices. Pediatrics, 110(5), e58.

Taylor, A. L., Ziesche, S., Yancy, C., Carson, P., D’Agostino, R., Jr., Ferdinand, K., et al. (2004). Combination of isosorbide dinitrate and hydralazine in blacks with heart failure. New England Journal of Medicine, 351(20), 2049-2057.

van Ryn, M., \& Burke, J. (2000). The effect of patient race and socio-economic status on physicians' perceptions of patients. Social Science \& Medicine, 50(6), 813-828.

Walters, S. J., \& Brazier, J. E. (2003). What is the relationship between the minimally important difference and health state utility values? The case of the SF-6D. Health Quality and Life Outcomes, 1(1), 4.

Walters, S. J., \& Brazier, J. E. (2005). Comparison of the minimally important difference for two health state utility measures: EQ-5D and SF-6D. Quality of Life Research, 14(6), $1523-1532$.

Williams, D. R. (1999). Race, socioeconomic status, and health. The added effects of racism and discrimination. Annals of the New York Academy of Sciences, 896, 173-188.

Williams, D. R., \& Jackson, P. B. (2005). Social sources of racial disparities in health. Health Affairs (Millwood), 24(2), 325-334.

Wong, M. D., Shapiro, M. F., Boscardin, W. J., \& Ettner, S. L. (2002). Contribution of major diseases to disparities in mortality. New England Journal of Medicine, 347(20), $1585-1592$.

Zimmerman, R. K., Santibanez, T. A., Janosky, J. E., Fine, M. J., Raymund, M., Wilson, S. A., et al. (2003). What affects influenza vaccination rates among older patients? An analysis from inner-city, suburban, rural, and Veterans Affairs practices. American Journal of Medicine, 114(1), 31-38. 